\title{
Toxicity of plant extracts containing pyrrolizidine alkaloids using alternative invertebrate models
}

\author{
OANA CRISTINA SEREMET ${ }^{1}$, OCTAVIAN TUDOREL OLARU ${ }^{1}$, CLAUDIA MARIA GUTU $^{1}$, \\ GEORGE MIHAI NITULESCU $^{1}$, MIHAELA ILIE ${ }^{1 *}$, SIMONA NEGRES ${ }^{1}$, CRISTINA ELENA ZBARCEA ${ }^{1}$, \\ CARMEN NICOLETA PURDEL ${ }^{1}$, DEMETRIOS A. SPANDIDOS ${ }^{2}$, ARISTIDES M. TSATSAKIS ${ }^{3}$, \\ MICHAEL D. COLEMAN ${ }^{4}$ and DENISA MARILENA MARGINA ${ }^{1}$ \\ ${ }^{1}$ Faculty of Pharmacy, University of Medicine and Pharmacy 'Carol Davila', 020956 Bucharest, Romania; \\ ${ }^{2}$ Laboratory of Clinical Virology, School of Medicine, University of Crete, 71003 Heraklion; ${ }^{3}$ Department of \\ Forensic Sciences and Toxicology, Faculty of Medicine, University of Crete, 71409 Heraklion, Crete, \\ Greece; ${ }^{4}$ School of Life and Health Sciences, Aston University, B4 7ET Birmingham, UK
}

Received February 9, 2018; Accepted March 26, 2018

DOI: $10.3892 / \mathrm{mmr} .2018 .8795$

\begin{abstract}
Pyrrolizidine alkaloids (PAs) are a widespread class of hepatotoxic heterocyclic organic compounds found in approximately $3 \%$ of world flora. Some PAs have been shown to have genotoxic and carcinogenic effects. The present study focuses on the toxicity effects of four dry extracts obtained from medicinal plants (Senecio vernalis, Symphytum officinale, Petasites hybridus and Tussilago farfara), on two aquatic organisms, Artemia salina and Daphnia magna, and the correlation with their PAs content. A new GC-MS method, using a retention time (TR)-5MS type capillary column was developed. PAs Kovats retention indices, for this type of column were computed for the first time. The lethal dose $50 \%\left(\mathrm{LC}_{50}\right)$ values for the two invertebrate models were correlated (Pearson 's coefficient, $>0.9$ ) and the toxicity was PA concentration-dependent, for three of the four extracts. All
\end{abstract}

Correspondence to: Dr Octavian Tudorel Olaru, Faculty of Pharmacy, University of Medicine and Pharmacy 'Carol Davila', 6 Traian Vuia, 020956 Bucharest, Romania

E-mail: octav_olaru2002@yahoo.com

Professor Aristides M. Tsatsakis, Department of Forensic Sciences and Toxicology, Faculty of Medicine, University of Crete, 71409 Heraklion, Crete, Greece

E-mail: tsatsaka@uoc.gr

\section{"Deceased}

Abbreviations: PAs, pyrrolizidine alkaloids; PANOs, pyrrolizidine alkaloids N-oxides; SEN, Senecio vernalis extract; SYM, Symphytum officinale extract; PET, Petasites hybridus extract; TUSS, Tussilago farfara extract; RI, Kovats retention indices; $\mathrm{T}_{\mathrm{R}}$, retention time; dw, dry material; $\mathrm{LC}_{50}$, lethal dose $50 \%$; CI $95 \%, 95 \%$ confidence interval

Key words: pyrrolizidine alkaloids, Artemia salina, Daphnia magna, acute toxicity, medicinal plants, GC-MS analysis tested extracts were found to be toxic in both aquatic organism models. The results can be used to develop a GC-MS validated method for the assay of PAs in medicinal plants with a further potential application in the risk assessment study of PAs toxicity in humans.

\section{Introduction}

Over the last few decades, there has been increasing interest in the use of natural compounds, often from traditional medicine, as adjuvants and even as replacement of allopathic treatment (1). While prescription medicines have well-defined chemical composition and are supported by evidence-based published studies, in terms of their efficacy and toxicity, this has not been the case with traditional medicines. Indeed, the popular misconception that all 'natural' products are safe has tended to discourage investigation into their potential toxicity (2). Such problems arise even in the case of certain therapeutic teas which have even special monographs in Pharmacopoeias (3).

Pyrrolizidine alkaloids (PAs) are heterocyclic organic compounds, which are found in more than 6,000 plant species (approximately 3\% of world flora) as secondary metabolites (4). Approximately $95 \%$ of PAs are found in plants from Senecioneae and Eupatorieae tribes (Asteraceae), in several genera of the Boraginaceae family, in the genus Crotalaria (Fabaceae), and in some genera of the Orchidaceae family (5). PAs are esters of heterocyclic amino alcohols termed necines (Fig. 1), with aliphatic monocarbonic or dicarbonic acids (necine acids). These alkaloids can be found, in plants, both as a free base and as the corresponding pyrrolizidine alkaloids N-oxides (PANOs) (4).

The toxicity of PAs is structure-dependent as the presence of a double bond in the necine base, often referred to as 1,2-unsaturated PAs or dehydroPAs, has been associated with greater toxicity in comparison with the saturated necine bases (6). PAs are essentially stored in the plant as protoxins, in the benign $\mathrm{N}$-oxide form, whereas in the gastrointestinal 
tract of animals they are reduced to the corresponding amine becoming toxic (7).

Several cases of poisoning, some fatal, due to the use of medicinal plants containing PAs have been reported. In addition, the consumption of cereals and bakery products contaminated with seeds of species containing PAs has been involved in mass poisonings in rural areas of Afghanistan, India, South Africa and the former USSR (8). Poisoning can manifest as acute or subacute veno-occlusive disease with specific symptoms such as persistent hepatomegaly, which in most cases, progresses to cirrhosis (9). Some PAs have been shown to have genotoxic, mutagenic, teratogenic and carcinogenic effects (10). Thus, research into the presence, identification and quantification of PAs as well as their toxicity is important regarding human consumption of food from plant origin in general and medicinal plants particularly (11). It is thus important that commercially available beverages (infusions) of plants should be tested for their qualitative and quantitative levels of PAs.

Petasites hybridus (butterbur), Tussilago farfara (coltsfoot) and Symphytum officinale (comfrey) are species traditionally used in phytotherapy and are commonly found in specialized shops for tea beverages. Petasites hybridus root has been used in the treatment of migraine, dysmenorrhea, asthma and allergic rhinitis (12). Tussilago farfara leaves are mainly used to relieve dry cough and other respiratory disease symptoms (13). Findings have shown that a methanolic extract obtained from the leaves and stems of this species could be used in anti-cancer therapy as a TNF-related apoptosis-inducing ligand sensitizer (14). Symphytum officinale root is used in cases of gastro-intestinal and respiratory tract diseases (4), whilst Senecio vernalis (spring groundsel) is not as commonly used in phytotherapy. However, the aerial parts of Senecio species, under the generic name of Senecionis herba, have been used for their antidiarrheal, diuretic, emmenagogue, galactagogue and expectorant properties (15).

Daphnia magna (Straus) is a freshwater zooplankton of the order Cladocera that has been routinely used as a standard test species in ecotoxicology (16) due to their ease of handling in the laboratory, and also to its relatively high sensitivity to a large number of toxicants. Daphnia magna are sexually parthenogenic and their clonal reproduction offers the supreme advantage of genetic uniformity (17). Artemia salina is a species of brine shrimp from the Anostraca order, extensively used in ecotoxicology, due to the reliability, feasibility and cost-effectiveness of the tests (18).

Most toxicity studies of natural products containing PAs have been carried out on laboratory animals using isolated alkaloids including lasiocarpine, senkirkine, retrorsine, seneciphylline, and riddelliine (19). The toxicity of different plant extracts obtained from the four studied plant species was investigated on cell cultures, bacteria or animals (20-23). To the best of our knowledge, the effect of these species on aquatic species has not been studied so far.

The present study focuses on the PAs content in some extracts obtained from the aforementioned plants. To test their toxicity upon the two in vivo invertebrate models, Artemia salina and Daphnia magna, and the PAs content was correlated with the toxic effect.

\section{Materials and methods}

Dry plant extracts. Coltsfoot leaves, common butterbur roots teas (produced by Stef Mar, Ltd., Ramnicu Valcea, Romania) and comfrey roots tea (produced by Fares, Orastie, Romania) were purchased from retail stores. Senecio vernalis aerial part was harvested in May 2013, from Craiova Botanical Garden (Craiova, Romania), naturally dried and conserved in laboratory conditions. The morphological characters of the vegetal material were compared with the ones quoted by literature. A voucher specimen is available in the collection of the Department of Botany and Cell Biology, 'Carol Davila' University of Medicine and Pharmacy (Bucharest, Romania), and at 'Dimitrie Brandza' Botanical Garden (Bucharest, Romania; no. 405789).

The dry extracts were obtained as previously described (24). Briefly, the dried plants were ground (Tyler mesh 48), and $20 \mathrm{~g}$ of each plant material were refluxed twice for $2 \mathrm{~h}$ with $1,000 \mathrm{ml}$ of $50 \%$ methanol acidified with citric acid to $\mathrm{pH} 2.0-3.0$. The combined extracts were evaporated, under reduced pressure with a rotary evaporator system (Buchi, Flawil, Switzerland) to about $300 \mathrm{ml}$ and atomized with a Mini Spray Dryer B-290 (Buchi). The extracts were coded as follows: SEN (Senecio vernalis), SYM (Symphytum officinale), PET (Petasites hybridus) and TUSS (Tussilago farfara).

GC-MS analysis. For the PAs content assay, $2 \mathrm{~g}$ of SEN and SYM and $4 \mathrm{~g}$ of PET and TUSS were dissolved in $30 \mathrm{ml}$ of methanol acidified with $50 \%$ citric acid to $\mathrm{pH}$ 2.0-3.0. After complete dissolution, zinc powder (Merck KGaA, Darmstadt, Germany) was added in excess and the solutions were stirred for $3 \mathrm{~h}$ using a magnetic stirrer (HI 190M; Hanna Instruments, Woonsocket, RI, USA) to convert PANOs to PAs. After filtration, the solutions were purified by liquid-liquid extraction twice with chloroform and twice with diethyl ether. The aqueous solutions were alkalinized with $25 \%$ aqueous ammonia ( $\mathrm{pH} \mathrm{9-10)} \mathrm{and} \mathrm{the} \mathrm{PAs} \mathrm{were} \mathrm{extracted} \mathrm{three} \mathrm{times}$ with $30 \mathrm{ml}$ of chloroform. The chloroform solutions were dried under nitrogen flow at room temperature, the residue was dissolved in $2 \mathrm{ml}$ methanol and filtered through a $0.2 \mu \mathrm{m}$ syringe filter (Pall Life Science, Port Washington, NY, USA), and analyzed by GC-MS.

Standard solutions in methanol (HPLC isocratic grade; Merck $\mathrm{KGaA}$ ) were prepared from a stock solution of senecionine $(200 \mathrm{mg} / \mathrm{ml}, \mathrm{GC} \geq 95 \%$; Carl Roth $\mathrm{GmbH} \&$ Co. KG, Karlsruhe, Germany). The GC-MS analysis was carried out on a Focus gas chromatograph (Thermo Fisher Scientific, Inc., Waltham, MA, USA) equipped with retention time (TR)-5MS (5\% phenyl polysilphenylene-siloxane) capillary column (30 m x $0.25 \mathrm{~mm}$ x $0.25 \mu \mathrm{m}$; Thermo Fisher Scientific, Inc.). The capillary column was directly coupled to a quadrupole mass spectrometer (DSQII; Thermo Fisher Scientific, Inc.).

Chromatographic conditions were as follows: Samples $(1 \mu \mathrm{l})$ were injected in the split mode using helium as carrier gas (flow rate of $1.0 \mathrm{ml} / \mathrm{min}$ ); the injector temperature was $225^{\circ} \mathrm{C}$ and column temperature program: $100^{\circ} \mathrm{C}$ for $1 \mathrm{~min}$; ramp to $200^{\circ} \mathrm{C}$ at $20^{\circ} \mathrm{C} / \mathrm{min}$; ramp to $300^{\circ} \mathrm{C}$ at $10^{\circ} \mathrm{C} / \mathrm{min}$; analysis performed at $300^{\circ} \mathrm{C}$, the ionization by electron impact at $70 \mathrm{eV}$; detection in full scan mode within the range $\mathrm{m} / \mathrm{z} 60-650$. In order to obtain the Kovats retention indices (RI), to be further used 

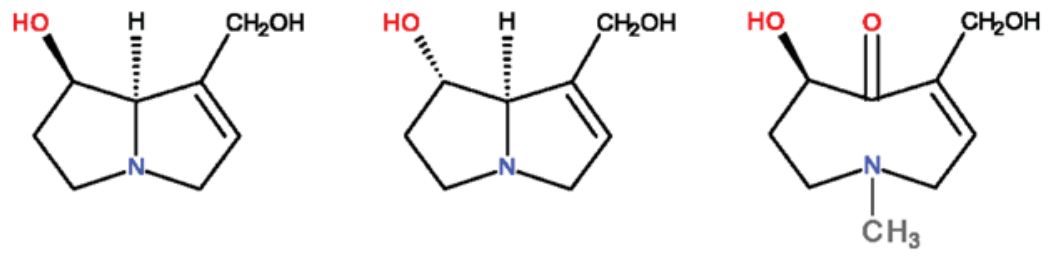

Retronecine

Heliotridine

Otonecine

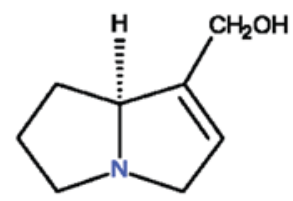

Supinidine

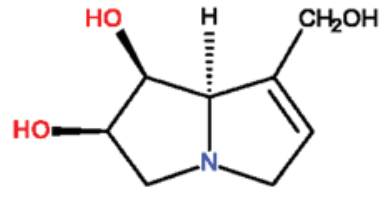

Crotanecine

Figure 1. The structures of major 1,2-unsaturated necines.

to compare the retention times obtained on the TR-5MS with those obtained on the DB-5 type column $(25,26)$, a mixture of n-alkanes (C21-C40) was analyzed at $300^{\circ} \mathrm{C}$ and maintained up to $40 \mathrm{~min}(26,27)$.

Identification of the PAs was carried out by means of the Kovats RI and the comparison of their mass spectra with those found in the NIST 0.2 database when available, and data from the literature (25-28). Due to the characteristic mass fragmentation pattern of PAs, a selected ion monitoring (SIM) method was used for the determination of retronecine/heliotridine type $(\mathrm{m} / \mathrm{z} 93,120$ and 136$)$ and otonecine type $(\mathrm{m} / \mathrm{z} 110,151$ and 168).

For the quantitative determination, senecionine was used as a standard for the calibration curve. The area obtained for each PA was interpolated on this curve and the results were expressed in milligrams senecionine equivalents per $100 \mathrm{~g}$ of dry material (dw).

The total amount of PAs obtained was compared to the results obtained for the same extracts with those obtained by a modified Ehrlich spectrophotometric method (24).

All the measurements were performed in triplicate. The results are expressed as means \pm standard deviation (SD).

\section{Toxicity assessment}

Artemia salina assay. Brine shrimp eggs were obtained from a local aquarium shop (Bucharest, Romania) and hatched for $48 \mathrm{~h}$ in breakers containing artificial sea water (36 g/l salinity) at $25 \pm 1^{\circ} \mathrm{C}$ under continuous aeration, in a plant growth chamber (Sanyo MLR-351 H; Sanyo, San Diego, CA, USA), using a $16 \mathrm{~h}$ photoperiod per day. The newly hatched nauplii were separated from the shells and transferred to fresh artificial sea water with a micropipette. The assay was performed in the growth chamber, under the conditions described above, using different concentrations of extracts $(1.0-1,000.0 \mu \mathrm{g} / \mathrm{ml})$ in artificial sea water with $1 \%$ DMSO, on 50 larvae in $500 \mu \mathrm{l}$ final volume of each dilution of the extracts. Concentrations varied for each extract and were chosen based on results obtained from preliminary studies. Artificial sea water with $1 \%$ DMSO was used as the negative control. After $24 \mathrm{~h}$, the number of surviving nauplii was counted and recorded. Larvae were considered dead only if they did not move their appendages for $10 \mathrm{sec}$ during observation (29-31).
Daphnia magna assay. The daphnids, maintained parthenogenetically in 'Carol Davila' University, Department of Pharmaceutical Botany and Cell Biology, were selected according to their size and kept in fresh synthetic water $(32,33)$ under continuous aeration, $24 \mathrm{~h}$ prior to the experiment. The assay was performed for the extracts in fresh synthetic water with $1 \%$ DMSO $(10-1,000 \mu \mathrm{g} / \mathrm{ml})$ in $15 \mathrm{ml}$ glass tubes, with 10 daphnids/tube. Concentrations for each extract were settled after several preliminary tests. Fresh synthetic with $1 \%$ DMSO was used as the control. Lethality was recorded after 24, 72 and $120 \mathrm{~h}$. The daphnids were considered dead only if they did not move their appendages for $30 \mathrm{sec}$ during observations (34). During the experiment the daphnids were kept at $25 \pm 1^{\circ} \mathrm{C}$ under continuous aeration, in a plant growth chamber (Sanyo MLR-351 H), using a $16 \mathrm{~h}$ photoperiod per day (35).

Statistical analysis. The toxicity tests were performed in duplicate. The lethality percentage was calculated and plotted against the logarithm of concentrations and the lethality-concentration curves were calculated using the least squares fit method. The lethal concentrations $\left(\mathrm{LC}_{50}\right)$ which produce a lethality value of 50 , were determined by interpolation on lethality-concentration curves. The upper and lower limits of the $95 \%$ confidence interval $(95 \% \mathrm{CI}$ ) were calculated. The correlation between the $\mathrm{LC}_{50}$ values for the two invertebrate models was determined by the use of Pearson coefficient. All calculations were performed using GraphPad Prism version 5.01 software (GraphPad Software, Inc., La Jolla, CA, USA).

\section{Results}

$G C$-MS analysis. Both the qualitative and quantitative analysis of the extracts were validated. Thus, the RI values were determined on a TR-5MS column. The consulted literature did not report any RI values for PAs using this type of column, but there were reports on a DB-5 type column $(25,26)$. Fletcher et al (27) analyzed the PAs from Crotalaria sp. by GS-MS using a TR-5MS column and observed that the same retention order for the compounds, although RI values were all 1.02-fold higher than those obtained on DB-5 columns. Similarly, our results showed that for the TR-5MS type column 
Table I. Pyrrolizidine alkaloid content and composition of SEN, PET, TUSS and SYM.

\begin{tabular}{|c|c|c|c|c|c|}
\hline Extract & PA (type) & $\mathrm{T}_{\mathrm{R}}(\min )$ & $\mathrm{RI}_{\mathrm{DB}-5}$ & $\mathrm{RI}_{\mathrm{TR}-5 \mathrm{MS}}$ & PA content ${ }^{\mathrm{a}}$ \\
\hline \multirow[t]{5}{*}{ SEN } & Senecivernine $(\mathrm{R})$ & 13.10 & 2,330 & 2,395 & 3.78 \\
\hline & Senecionine $(\mathrm{R})$ & 13.23 & 2,341 & 2,412 & 346.14 \\
\hline & Seneciphylline (R) & 13.45 & 2,360 & 2,439 & 40.40 \\
\hline & Integerrimine (R) & 13.77 & 2,402 & 2,481 & 26.26 \\
\hline & Senkirkine $(\mathrm{O})$ & 14.71 & 2,530 & 2,608 & 78.28 \\
\hline \multirow[t]{4}{*}{ SYM } & Intermedine $(\mathrm{R})$ & 11.97 & 2,188 & 2,253 & 7.48 \\
\hline & Symphytine (R) & 12.45 & 2,244 & 2,312 & 117.92 \\
\hline & Lasiocarpine $(\mathrm{H})$ & 12.55 & 2,257 & 2,325 & 31.64 \\
\hline & Symveridine (R) & 13.97 & 2,325 & 2,406 & 0.52 \\
\hline \multirow[t]{2}{*}{ TUSS } & Senecionine (R) & 13.23 & 2,341 & 2,412 & 0.74 \\
\hline & Senkirkine (O) & 14.66 & 2,530 & 2,604 & 2.44 \\
\hline \multirow[t]{3}{*}{ PET } & Senecionine (R) & 13.24 & 2,341 & 2,413 & 1.84 \\
\hline & Integerrimine (R) & 13.78 & 2,402 & 2,482 & 0.47 \\
\hline & Senkirkine $(\mathrm{O})$ & 14.69 & 2,530 & 2,605 & 0.86 \\
\hline
\end{tabular}

${ }^{a}$ Expressed in $\mathrm{mg}$ senecionine/100 g dry weight extract. SEN, Senecio vernalis extract; PET, Petasites hybridus extract; TUSS, Tussilago farfara extract; SYM, Symphytum officinale extract; PA, pyrrolizidine alkaloid; $\mathrm{T}_{\mathrm{R}}$, retention time; $\mathrm{RI}_{\mathrm{DB}-5}$, DB-5 (as in refs. 25,26); RI $\mathrm{TR}-5 \mathrm{MS}$, TR-5MS obtained RIs; R, retronecine type; O, otonecine type; $\mathrm{H}$, heliotridine type.

Table II. Comparison of the quantitative analysis results for the extracts.

\begin{tabular}{|c|c|c|}
\hline \multirow[b]{2}{*}{ Extract } & \multicolumn{2}{|c|}{$\begin{array}{c}\text { Total PAs } \\
\text { (mg senecionine/100 g dry weight extract) }\end{array}$} \\
\hline & GC-MS & Spectrophotometric ${ }^{a}$ \\
\hline SEN & 424.92 & 416.58 \\
\hline SYM & 150.24 & 157.56 \\
\hline PET & 2.11 & 2.31 \\
\hline TUSS & 0.97 & 0.74 \\
\hline
\end{tabular}

PAs, pyrrolizidine alkaloids; SEN, Senecio vernalis extract; SYM, Symphytum officinale extract; PET, Petasites hybridus extract; TUSS, Tussilago farfara extract. ${ }^{a}$ As in ref. (24)

the elution order of the PAs from the 4 extracts coincided with that reported in the literature for a DB-5 type column and the RI values were 1.03-fold higher (Table I). Therefore, we can assume that the retention times were correctly assigned.

For the quantitative analysis, the total amount of PAs obtained by the GC method was compared to the results of a spectrophotometric quantitative analysis which also quantified PAs, expressed as mg senecionine/100 g dry weight of each extract. Results are presented in Table II.

Toxicity assessment. Preliminary tests showed, in case of Artemia salina, that a lethality $>90 \%$ was caused by SEN (over $250 \mu \mathrm{g} / \mathrm{ml}$ ), TUSS (over $500 \mu \mathrm{g} / \mathrm{ml}$ ), PET (over $400 \mu \mathrm{g} / \mathrm{ml}$ ) and SYM (over $750 \mu \mathrm{g} / \mathrm{ml}$ ) (Table III). Lethality vs. the logarithm of concentration regression curves were afterwards plotted, and the $\mathrm{LC}_{50}$ and 95\% CIs $(\alpha=0.05)$ could be calculated (Table III).

In case of Daphnia magna SEN, TUSS and PET induced lethality of $>90 \%$ in the concentration range of $500-1,000 \mu \mathrm{g} / \mathrm{ml}$ and SYM at $1,000 \mu \mathrm{g} / \mathrm{ml}$. After logarithm of the concentration vs. lethality regression curves were plotted, $\mathrm{LC}_{50}$ could not be calculated for SYM at $24 \mathrm{~h}$, therefore it was considered $>2,000 \mu \mathrm{g} / \mathrm{ml}$. In all cases tested, the viability of the controls was $100 \%$.

\section{Discussion}

Even though the identification of PAs by GC-MS was first carried out in the early 1990s (25), their assay, mainly in plants used as therapeutic teas, remains of interest due to their potential toxicity (36-39). This report presents four plant extracts, which were analyzed for their qualitative and quantitative content in PAs: Senecio vernalis, Petasites hybridus, Tussilago farfara and Symphytum officinale. While the last three are commonly used in phytoterapy, Senecio vernalis was analyzed mainly for its already known high content of PAs (40), in an attempt to emphasize the risk of using PAs in therapy, if any. Moreover, while the extracts from the last three plants (PET, TUSS and SYM) were obtained from commercial teas (dry plant material), SEN extract was obtained from plants harvested and prepared similarly to teas (aerial parts were dried in the conditions in which common teas are dried) mainly as it contained a significant amount of senecionine.

A novel GC-MS method for the qualitative and quantitative determination of certain PAs from dry vegetable extracts of the four plants was developed using a TR-5MS capillary column. In order to compare our results to those already described in the literature, which used a DB-5 column $(25,26)$, the Kovats 
Table III. Acute toxicity of the extracts on Artemia salina and Daphnia magna.

\begin{tabular}{|c|c|c|c|c|c|}
\hline \multirow[b]{2}{*}{ Extract } & \multirow[b]{2}{*}{ Determination time (h) } & \multicolumn{2}{|c|}{ AS } & \multicolumn{2}{|c|}{$\mathrm{DM}$} \\
\hline & & $\mathrm{LC}_{50}(\mu \mathrm{g} / \mathrm{ml})$ & $95 \% \mathrm{CI}(\mu \mathrm{g} / \mathrm{ml})$ & $\mathrm{LC}_{50}(\mu \mathrm{g} / \mathrm{ml})$ & $95 \% \mathrm{CI}(\mu \mathrm{g} / \mathrm{ml})$ \\
\hline \multirow[t]{3}{*}{ SEN } & 24 & 131.22 & 109.14-148.59 & 95.67 & $95.58-95.75$ \\
\hline & 72 & nt & $\mathrm{nt}$ & 83.31 & $74.73-92.51$ \\
\hline & 120 & $\mathrm{nt}$ & nt & 5.28 & $\mathrm{a}$ \\
\hline \multirow[t]{3}{*}{ SYM } & 24 & 707.95 & $698.23-726.11$ & $\mathrm{~b}$ & $\mathrm{a}$ \\
\hline & 72 & nt & $\mathrm{nt}$ & 801.0 & $690.42-876.48$ \\
\hline & 120 & $\mathrm{nt}$ & nt & 412.3 & $237.18-565.89$ \\
\hline \multicolumn{6}{|l|}{ PET } \\
\hline & 24 & 296.48 & $269.15-343.56$ & 339.8 & $256.9-449.4$ \\
\hline & 72 & $\mathrm{nt}$ & nt & 178.6 & $51.42-620.3$ \\
\hline & 120 & nt & $\mathrm{nt}$ & 43.52 & $\mathrm{a}$ \\
\hline \multirow[t]{3}{*}{ TUSS } & 24 & 222.33 & $181.13-270.40$ & 509.04 & $\mathrm{a}$ \\
\hline & 72 & nt & $\mathrm{nt}$ & 189.97 & $105.02-459.30$ \\
\hline & 120 & nt & nt & 37.40 & $5.84-314.20$ \\
\hline
\end{tabular}

RI was computed for senecivernine, senecionine, seneciphylline, integerrimine, senkirkine, intermedine, symphytine, lasiocarpine, and symveridine. Both the order of elution for these compounds and the ratio between the retention times obtained in this study and those reported on a TR-5 column, of 1.03 , were the same as in the case of DB-5ms and DB-5 columns (27).

The largest amount of PAs was found in SEN (494.86 $\mathrm{mg} / 100 \mathrm{~g} \mathrm{dw}$ ), the predominant alkaloid being senecionine $(346.14 \mathrm{mg} / 100 \mathrm{~g} \mathrm{dw})$. For TUSS and PET the total PAs concentration was similar, $3.17 \mathrm{mg} / 100 \mathrm{~g} \mathrm{dw}$ and $3.18 \mathrm{mg} / 100 \mathrm{~g} \mathrm{dw}$, respectively. The main PA for PET was senecionine $(1.84 \mathrm{mg} / 100 \mathrm{gdw})$ and forTUSS the otonecine-type PA senkirkine $(2.44 \mathrm{mg} / 100 \mathrm{~g} \mathrm{dw})$. For SYM the total PAs concentration was $157.56 \mathrm{mg} / 100 \mathrm{~g}$ dw with symphytine as the main alkaloid $(117.92 \mathrm{mg} / 100 \mathrm{~g} \mathrm{dw})$. There is currently no international standard for the maximum allowable level of PAs in foods. However, in the Netherlands, the total PA content (including PANOs) in herbal preparations or herbal extracts, must not exceed $1 \mu \mathrm{g} / \mathrm{kg}$ (41). These limits are far exceeded by the tested extracts.

The toxicity of the extracts was determined using two experimental models of crustaceans - Artemia salina and Daphnia magna. These models can be predictive for the toxicity of extracts containing PAs in animals and humans because numerous studies have demonstrated the presence of cytochrome P450 in these organisms, enzymes needed for the biotransformation of PAs to the toxic pyrrole derivatives (42-45). The assays consisted in the exposure of the invertebrates at increasing concentrations of test substances and determination of the lethal concentrations $50 \%\left(\mathrm{LC}_{50}\right)$ at different time intervals $(24-120 \mathrm{~h})$. Substances with $\mathrm{LC}_{50}<1,000 \mu \mathrm{g} / \mathrm{ml}$ are considered toxic (46).
In case of Artemia salina, the low $\mathrm{LC}_{50}$ obtained for SEN $(131.22 \mu \mathrm{g} / \mathrm{ml})$ indicates that this extract is the most toxic of those studied. TUSS and PET are approximately 1.5-fold and 2.3-fold less toxic and SYM is about 5.4-fold less toxic. The CIs $(\mathrm{P}<0.05)$ could be calculated for all extracts, and they presented very high limits for PET and TUSS, but were narrow for SEN (approximately $50 \mu \mathrm{g} / \mathrm{ml}$ ) and SYM (approximately $30 \mu \mathrm{g} / \mathrm{ml}$ ). It should be noted that all tested extracts were found to be toxic in the case of this species.

Concerning Daphnia magna, it was observed that the extracts were generally toxic in the following order: SEN $>$ PET $>$ TUSS $>$ SYM. Thus, SEN has the highest toxicity, TUSS and PET exhibit similar toxicity, with $\mathrm{LC}_{50}$ values being very similar, particularly on the 3rd and 5th day. SYM is substantially non-toxic at $24 \mathrm{~h}$, has low toxicity after $72 \mathrm{~h}$ and moderate after $120 \mathrm{~h}$ of exposure.

In order to determine whether there is a correlation between the $\mathrm{LC}_{50}$ values obtained from Artemia salina and Daphnia magna (at 24, 72 and 120 h) assays for each extract, Pearson coefficient was calculated for the pairs Artemia salina (at $24 \mathrm{~h}$ ) and Daphnia magna at 24, 48 and $72 \mathrm{~h}$. The values obtained were greater than 0.97 , which indicates a strong positive Pearson correlation. SEN, the extract with the highest concentration of PAs, exhibits the highest toxicity and the $\mathrm{LC}_{50}$ obtained for PET and TUSS, extracts that have similar PAs concentrations, had similar values. SYM, the extract with the second PAs concentration $157.56 \mathrm{mg} / 100 \mathrm{~g}$ $\mathrm{dw}$, presented in both cases the lowest toxicity. This result could be explained by the fact that Symphytum officinale contained senecionine under the limit of detection, if any. Alternately, other components present in the extract could reduce the effect of existing PAs in SYM. Further studies are to focus on both hypotheses. 
The $\mathrm{LC}_{50}$ computed for each extract corresponded to an $\mathrm{LC}_{50}$ of total PAs of 2.15-1,063 $\mu \mathrm{g} / 1$ for the Artemia salina assay and $0.36-1,203 \mu \mathrm{g} / \mathrm{l}$ for the Daphnia magna assay. Mulder et al (47) determined the occurrence of PAs in herbal teas from different European countries. For the teas containing no PA-producing plants $(n=166)$, in the majority of samples (91\%), one or more PAs were detected, with a mean total value of $6.13 \mu \mathrm{g} / 1$. For the tea infusion obtained from PA-producing plants $(\mathrm{n}=12)$, the PAs levels were 2.4-414 $\mu \mathrm{g} / \mathrm{l}$. It can be seen that PAs levels in these infusions are in the same range as the $\mathrm{LC}_{50}$ for the two aquatic organisms.

In conclusion, all four extracts containing PAs were shown to be toxic in the model tests on aquatic organisms. Toxicity increased with the PAs concentration, except for the extract from Symphytum officinale. PAs $\mathrm{LC}_{50}$ was in the same range as PAs levels found in some herbal tea infusion from Europe.

\section{Acknowledgements}

In memoriam: The authors would like to respectfully dedicate this article to Ms. Mihaela Ilie, who passed away on January 1, 2018.

\section{Funding}

The authors acknowledge the financial support offered by UEFISCDI (Romania - grant no. 8BM/2016) and NRF (South Africa), through the Romania - South Africa Joint Collaboration.

\section{Availability of data and materials}

All data generated or analyzed during this study are included in this published article.

\section{Authors' contributions}

OCS, OTO, MI and DMM defined the research theme. OCS, OTO, CMG and GMN designed the methods and experiments and performed the laboratory experiments. SN, CEZ and CNP analyzed and interpreted the data. OCS and OTO wrote the manuscript. MI, DAS, MDC, AMT and DMM critically revised the paper for important intellectual content. AMT and DMM gave the final approval of the version to be published. All authors read and approved the final manuscript.

\section{Ethics approval and consent to participate}

Not applicable.

\section{Consent for publication}

Not applicable.

\section{Competing interests}

Demetrios A. Spandidos is the Editor-in-Chief for the journal, but had no personal involvement in the reviewing process, or any influence in terms of adjudicating on the final decision, for this article.

\section{References}

1. Han E, Johnson N, DelaMelena T, Glissmeyer M and Steinbock K: Alternative therapy used as primary treatment for breast cancer negatively impacts outcomes. Ann Surg Oncol 18: 912-916, 2011.

2. Margină D, Ilie M, Grădinaru D, Androutsopoulos VP, Kouretas D and Tsatsakis AM: Natural products - friends or foes? Toxicol Lett 236: 154-167, 2015.

3. Shikov AN, Pozharitskaya ON, Makarov VG, Wagner H, Verpoorte R and Heinrich M: Medicinal plants of the Russian Pharmacopoeia; their history and applications. J Ethnopharmacol 154: 481-536, 2014.

4. Roeder E: Medicinal plants in Europe containing pyrrolizidine alkaloids. Pharmazie 50: 83-98, 1995.

5. Reimann A, Nurhayati N, Backenköhler A and Ober D: Repeated evolution of the pyrrolizidine alkaloid-mediated defense system in separate angiosperm lineages. Plant Cell 16: 2772-2784, 2004.

6. Hartmann T: Chemical ecology of pyrrolizidine alkaloids. Planta 207: 483-495, 1999.

7. Coulombe RA Jr: Pyrrolizidine alkaloids in foods. In: Advances in Food and Nutrition Research. Taylor SL (ed). Vol 45. Elsevier Science, Ltd., Oxford, UK, pp61-99, 2003.

8. Neuman MG, Cohen L, Opris M, Nanau RM and Hyunjin J: Hepatotoxicity of pyrrolizidine alkaloids. J Pharm Pharm Sci 18: 825-843, 2015.

9. Prakash AS, Pereira TN, Reilly PEB and Seawright AA: Pyrrolizidine alkaloids in human diet. Mutat Res 443: 53-67, 1999.

10. Chen T, Mei N and Fu PP: Genotoxicity of pyrrolizidine alkaloids. J Appl Toxicol 30: 183-196, 2010.

11. Stahlmann R and Horvath A: Risks, risk assessment and risk competence in toxicology. Ger Med Sci 13: Doc09, 2015 (In English, German).

12. Fiebich BL, Grozdeva M, Hess S, Hüll M, Danesch U, Bodensieck A and Bauer R: Petasites hybridus extracts in vitro inhibit COX-2 and PGE2 release by direct interaction with the enzyme and by preventing p42/44 MAP kinase activation in rat primary microglial cells. Planta Med 71: 12-19, 2005.

13. Nedelcheva A, Kostova $\mathrm{N}$ and Sidjimov A: Pyrrolizidine alkaloids in Tussilago farfara from Bulgaria. Biotechnol Biotechnol Equip 29 (Suppl 1): S1-S7, 2015.

14. Lee HJ, Cho HS, Jun SY, Lee JJ, Yoon JY, Lee JH, Song HH, Choi SH, Kim SY, Saloura V, et al: Tussilago farfara L. augments TRAIL-induced apoptosis through MKK7/JNK activation by inhibition of MKK 7 TIPRL in human hepatocellular carcinoma cells. Oncol Rep 32: 1117-1123, 2014.

15. Mogosanu DG, Pintea A, Bejenaru LE, Bejenaru C, Rău G and Popescu H: HPLC analysis of carotenoids from Senecio vernalis and S. jacobaea (Asteraceae). Farmacia 57: 780-786, 2009.

16. Martins J, Oliva Teles L and Vasconcelos V: Assays with Daphnia magna and Danio rerio as alert systems in aquatic toxicology. Environ Int 33: 414-425, 2007.

17. Toumi H, Boumaiza M, Millet M, Radetski CM, Camara BI, Felten V and Ferard J-F: Investigation of differences in sensitivity between 3 strains of Daphnia magna (crustacean Cladocera) exposed to malathion (organophosphorous pesticide). J Environ Sci Health B 50: 34-44, 2015.

18. Nunes BS, Carvalho FD, Guilhermino LM and Van Stappen G: Use of the genus Artemia in ecotoxicity testing. Environ Pollut 144: 453-462, 2006.

19. Fu PP, Xia Q, Lin G and Chou MW: Pyrrolizidine alkaloids - genotoxicity, metabolism enzymes, metabolic activation, and mechanisms. Drug Metab Rev 36: 1-55, 2004.

20. Behninger C, Abel G, Röder E, Neuberger V and Göggelmann W: Studies on the effect of an alkaloid extract of Symphytum officinale on human lymphocyte cultures. Planta Med 55: 518-522, 1989 (In German)

21. Chou MW and Fu PP: Formation of DHP-derived DNA adducts in vivo from dietary supplements and chinese herbal plant extracts containing carcinogenic pyrrolizidine alkaloids. Toxicol Ind Health 22: 321-327, 2006.

22. Benedek B, Ziegler A and Ottersbach P: Absence of mutagenic effects of a particular Symphytum officinale L. liquid extract in the bacterial reverse mutation assay. Phytother Res 24: 466-468, 2010. 
23. Gomes MFPL, de Oliveira Massoco C, Xavier JG and Bonamin LV: Comfrey (Symphytum officinale. 1.) and experimental hepatic carcinogenesis: A short-term carcinogenesis model study. Evid Based Complement Alternat Med 7: 197-202, 2010.

24. Seremet O, Olaru OT, Bălălău D and Negres S: The effect of certain plant extracts containing pyrrolizidine alkaloids on Lactuca sativa radicle growth. Rom J Biophys 24: 1-9, 2014.

25. Witte L, Rubiolo P, Bicchi C and Hartmannt T: Comparative analysis of pyrrolizidine alkaloids from natural sources by gas chromatography-mass spectrometry. Phytochemistry 32 : 187-196, 1992.

26. Gardner DR, Thorne MS, Molyneux RJ, Pfister JA and Seawright AA: Pyrrolizidine alkaloids in Senecio madagascariensis from Australia and Hawaii and assessment of possible livestock poisoning. Biochem Syst Ecol 34: 736-744, 2006.

27. Fletcher MT, McKenzie RA, Blaney BJ and Reichmann KG: Pyrrolizidine alkaloids in Crotalaria taxa from northern Australia: Risk to grazing livestock. J Agric Food Chem 57: 311-319, 2009.

28. Asres K, Sporer F and Wink M: Occurrence of pyrrolizidine alkaloids in three Ethiopian Solanecio species. Biochem Syst Ecol 36: 399-407, 2008

29. GuŢu CM, Olaru OT,Purdel NC,Ilie M,NeamŢu MC, Dănciulescu Miulescu R, Avramescu ET and Margină DM: Comparative evaluation of short-term toxicity of inorganic arsenic compounds on Artemia salina. Rom J Morphol Embryol 56: 1091-1096, 2015

30. Olaru OT, Venables L, VAN DE Venter M, Nitulescu GM, Margina D, Spandidos DA and Tsatsakis AM: Anticancer potential of selected Fallopia Adans species. Oncol Lett 10: 1323-1332, 2015.

31. Socea LI, Socea B, Saramet G, Barbuceanu SF, Draghici C, Constantin VD and Olaru OT: Synthesis and cytotoxicity evaluation of new 5H-dibenzo[a,d] [7]annulen-5-yl acetylhydrazones. Rev Chim 66: 1122-1127, 2015.

32. Nitulescu GM, Draghici C and Olaru OT: New potential antitumor pyrazole derivatives: Synthesis and cytotoxic evaluation. Int J Mol Sci 14: 21805-21818, 2013.

33. OECD guidelines for the testing of chemicals, section 2: 'Daphnia sp., acuteimmobilizationtest'.http://www.oecd-ilibrary. org/docserver/download/9720201e.pdf. Accessed Feb 28, 2018.

34. Olaru OT, Seremet OC, Petrescu M, Salagean A, Velescu B and Nitulescu GM: Toxicity evaluation and polyphenols assessment of some extracts from indigenous Euphorbia species. Rom J Biophys 24: 43-54, 2014.
35. Fan W, Cui M, Liu H, Wang C, Shi Z, Tan C and Yang X Nano- $\mathrm{TiO}_{2}$ enhances the toxicity of copper in natural water to Daphnia magna. Environ Pollut 159: 729-734, 2011.

36. IPCS: Environmental health criteria 80: Pyrrolizidine alkaloids. World Health Organization, Geneva, 1988. http://www.inchem. org/documents/ehc/ehc/ehc080.htm. Accessed Feb 28, 2018

37. European Medicines Agency: Public statement on the use of herbal medicinal products containing toxic, unsaturated pyrrolizidine alkaloids (PAs). http://www.ema.europa. eu/docs/en_GB/document_library/Public_statement/2014/12/ WC500179559.pdf. Accessed Feb 28, 2018.

38. Seremet O, Olaru OT, Ilie M, Negres S and Bălălău D: HPTLC evaluation of the pyrollizidine alkaloid senecionine in certain phytochemical products. Farmacia 61: 756-763, 2013.

39. Seremet OC, Bărbuceanu F, Ionică FE, Margină DM, GuTu CM, Olaru OT, Ilie M, Gonciar V, Negres S and ChiriŢă C: Oral toxicity study of certain plant extracts containing pyrrolizidine alkaloids. Rom J Morphol Embryol 57: 1017-1023, 2016.

40. Aniszewski T: Alkaloids - Secrets of Life: Aklaloid Chemistry, Biological Significance Applications and Ecological Role. 1st edition. Elsevier, Amsterdam, p167, 2007.

41. Centre for Food Safety: Chemical hazard evaluation: Pyrrolizidine alkaloids in food. http://www.cfs.gov.hk/english/ programme/programme_rafs/files/Pyrrolizidine_Alkaloids_in_ Food_e.pdf. Accessed March 6, 2018.

42. James MO: Cytochrome P450 monooxygenases in crustaceans. Xenobiotica 19: 1063-1076, 1989.

43. James MO and Boyle SM: Cytochromes P450 in crustacea. Comp Biochem Physiol C Pharmacol Toxicol Endocrinol 121: 157-172, 1998.

44. Rewitz KF, Styrishave B, Løbner-Olsen A and Andersen O: Marine invertebrate cytochrome P450: Emerging insights from vertebrate and insects analogies. Comp Biochem Physiol C Toxicol Pharmacol 143: 363-381, 2006.

45. Solé M and Livingstone DR: Components of the cytochrome P450-dependent monooxygenase system and 'NADPH-independent benzo[a]pyrene hydroxylase' activity in a wide range of marine invertebrate species. Comp Biochem Physiol C Toxicol Pharmacol 141: 20-31, 2005.

46. Meyer BN, Ferrigni NR, Putnam JE, Jacobsen LB, Nichols DE and McLaughlin JL: Brine shrimp: A convenient general bioassay for active plant constituents. Planta Med 45: 31-34, 1982.

47. Mulder PPJ, López Sánchez P, These A, Preiss-Weigert A and Castellari M: Occurrence of pyrrolizidine alkaloids in food. European Food Safety Authority, p116, 2015. 